\title{
BURSTS OF MICROWAVE RADIO EMISSION ASSOCIATED WITH SOLAR FLARES
}

\author{
G. B. GELFREICH, v. N. IKHSANOVA, N. L. KAİDANOVSKIÍ, \\ N. S. SOBOLEVA, G. M. TIMOFEEVA, AND V. N. UMETSKIİ \\ Pulkovo Observatory, Leningrad, U.S.S.R.
}

Bursts of solar radio emission which coincide in time with solar flares are occasionally observed over the whole frequency range up to $35,000 \mathrm{Mc} / \mathrm{s}$. The purpose of this paper is to describe briefly some bursts observed at Pulkovo at wavelength $\lambda=3.2 \mathrm{~cm}$.

The observations were made with a polarimeter using a 4-meter diameter reflector [1, 2] and the large Pulkovo radio telescope [3, 4] with a fan-beam diagram about 2 minutes of arc wide. Nine bursts have been recorded with certainty during 250 hours of observations since 1957 July, seven of them being identified in time with solar flares. The results of these observations are arranged in Table $I$. The records of polarized flux density are shown in Figs. 1 to 4 and in Fig. 6. The record of random polarization flux density is also shown in Fig. 6. The flare data were taken from the bulletin Solar Data and the Fraunhofer Institute maps of the sun (Fig. 5).

The drift-curves of the sun through the aerial diagram at the burst moments are shown in Figs. 1 and 2. The similar drift-curves taken after the bursts are shown in the same figures. The right-hand curve in Fig. 1 is their difference.

The percentage of circular polarization of bursts 5,7 , and 9 was measured at the decreasing branch of the intensity curve. The sign of polarization of the dominating sunspot group is given in column 9 beside the burst sign of polarization. The size of bursts 1 and 8 was obtained by the large radio telescope.* The heights of bursts 1 and $5[5,6]$ were derived from the difference between the burst and flare positions, assuming that the burst is generated in the region just over the flare.

The brightness temperatures determined by assuming the burst has the same area as the flare are put in parentheses. The identity of these temperatures with measured ones in occurrences 5 and 8 justifies this assumption. In cases 3 and 6 the percentage of polarization was assumed to be about 10 per cent while the brightness temperatures were being computed.

The observations available are not numerous enough for any statistical consideration. Nevertheless, some prominent features of the bursts observed can be summarized:

* The recent interferometer measurements were carried out by M. R. Kundu [7]. The sizes obtained ranged from 0.8 to 2.5 , being in reasonable agreement with our results. 
TABLE I

\begin{tabular}{|c|c|c|c|c|c|c|c|c|c|c|c|c|c|}
\hline \multirow{3}{*}{ 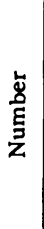 } & \multirow{3}{*}{ 苋 } & \multirow{3}{*}{ 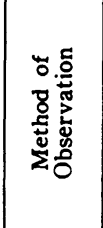 } & \multicolumn{3}{|c|}{ Universal Time } & \multirow{3}{*}{ 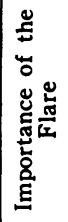 } & \multirow{2}{*}{\multicolumn{2}{|c|}{$\begin{array}{c}\text { Flux Density at } \\
\text { Maximum } \\
\left(10^{-22} \mathrm{w} \mathrm{m}^{-2}(\mathrm{c} / \mathrm{s})^{-1}\right.\end{array}$}} & \multirow{3}{*}{ 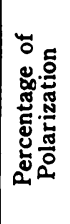 } & \multirow{3}{*}{ 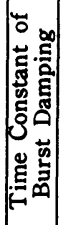 } & \multirow{3}{*}{ in } & \multirow{3}{*}{ 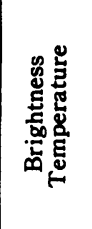 } & \multirow{3}{*}{ 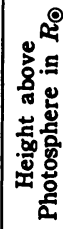 } \\
\hline & & & \multirow{2}{*}{ 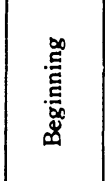 } & \multirow[b]{2}{*}{ 乨 } & \multirow[b]{2}{*}{ 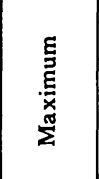 } & & & & & & & & \\
\hline & & & & & & & 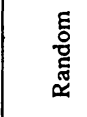 & 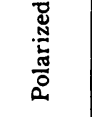 & & & & & \\
\hline 1 & 2 & 3 & 4 & 5 & 6 & 7 & 8 & 9 & 10 & 11 & 12 & 13 & 14 \\
\hline 1 & $\begin{array}{c}1957 \\
\text { Aug } 28\end{array}$ & $\begin{array}{l}P \\
O\end{array}$ & $\begin{array}{ll}\mathrm{h} & \mathrm{m} \\
& \\
8 & 10\end{array}$ & $\begin{array}{cc}\mathrm{h} & \mathrm{m} \\
<14 & \\
13 & 39\end{array}$ & $\begin{array}{rr}\mathrm{h} & \mathrm{m} \\
10 & 00 \\
9 & 55\end{array}$ & 3 & 100 & $10_{L}$ & 10 & $\frac{m}{-}$ & 一 & $\left(10^{\circ}\right)$ & $\begin{array}{r}0.2 \\
\pm 0.1\end{array}$ \\
\hline 2 & $\begin{array}{c}1957 \\
\text { Sep } 27 \\
\end{array}$ & $P$ & - & - & $10 \quad 04$ & & - & $7 \boldsymbol{R}$ & - & - & - & - & - \\
\hline 3 & $\begin{array}{c}1957 \\
\text { Sep } 28\end{array}$ & $\begin{array}{l}P \\
O\end{array}$ & $\begin{array}{ll}9 & 12 \\
9 & 12\end{array}$ & $\begin{array}{ll}9 & 15 \\
9 & 40\end{array}$ & $\begin{array}{lr}9 & 13.5 \\
9 & 14\end{array}$ & $1+$ & - & $10_{L}$ & - & 0.5 & - & $\left(10^{7}\right)$ & - \\
\hline 4 & $\begin{array}{c}1958 \\
\operatorname{Jan} 25\end{array}$ & $\begin{array}{c}P \\
\lambda=2 \mathrm{~cm} \\
O\end{array}$ & $\frac{\overline{-}}{933}$ & $\begin{array}{ll}10 & 50 \\
11 & - \\
11 & 07\end{array}$ & $\begin{array}{ll}10 & 05 \\
10 & 05 \\
10 & 02\end{array}$ & $2+$ & $\begin{array}{l}105 \\
120\end{array}$ & $\frac{10_{R}}{-}$ & 10 & - & & $\left(\begin{array}{c}\left(4 \times 10^{\circ}\right) \\
873\end{array}\right)$ & - \\
\hline 5 & $\begin{array}{c}1958 \\
\text { Mar } 3\end{array}$ & $\begin{array}{c}L R ; P \\
\quad O\end{array}$ & $\begin{array}{cc}10 & 11.1 \\
10 & 07\end{array}$ & $\begin{array}{ll}10 & 50 \\
11 & 10 \\
\end{array}$ & $\begin{array}{ll}10 & 12 \\
10 & 21\end{array}$ & 3 & 3000 & $-L$ & 7 & 8 & $\begin{array}{l}2^{\prime} \\
1327\end{array}$ & $\begin{array}{l}10^{8} \\
\left(10^{8}\right)\end{array}$ & $\begin{array}{l}0.1 \pm \\
0.03\end{array}$ \\
\hline 6 & $\begin{array}{c}1958 \\
\text { Mar } 21\end{array}$ & $\begin{array}{l}P \\
O\end{array}$ & $\begin{array}{ll}10 & 19 \\
10 & 16\end{array}$ & $\begin{array}{ll}10 & 21 \\
10 & 46\end{array}$ & $\begin{array}{ll}10 & 20 \\
10 & 22\end{array}$ & $1+$ & - & $>10_{R}$ & - & 0.3 & - & $\left(>10^{7}\right)$ & - \\
\hline 7 & $\begin{array}{c}1958 \\
\text { Mar } 22\end{array}$ & $\begin{array}{l}P \\
P\end{array}$ & $\begin{array}{rr}9 & 30 \\
10 & 43\end{array}$ & $\begin{array}{rr}9 & 55 \\
12 & \end{array}$ & $\begin{array}{rr}9 & 40 \\
10 & 55\end{array}$ & & - & $\begin{array}{l}25_{L} \\
98_{L}\end{array}$ & $\begin{array}{l}- \\
8\end{array}$ & $\begin{array}{r}- \\
5\end{array}$ & - & - & - \\
\hline 8 & $\begin{array}{c}1958 \\
\text { Mar } 23\end{array}$ & $\begin{array}{l}L R \\
O\end{array}$ & $\left(\begin{array}{rr}10 & 01\end{array}\right)$ & $\left(\begin{array}{cc}10 & 07 \\
10 & 57\end{array}\right)$ & $\begin{array}{rr}9 & 58 \\
10 & 05 \\
\end{array}$ & $\begin{array}{l}2+ \\
3+ \\
\end{array}$ & $10^{4}$ & - & - & - & $\begin{array}{r}2 \\
1119 \\
1236 \\
\end{array}$ & $\begin{array}{l}3 \times 10^{8} \\
\left(2 \times 10^{8}\right) \\
\end{array}$ & - \\
\hline 9 & $\begin{array}{c}1958 \\
\text { Apr } 7\end{array}$ & $\begin{array}{l}P \\
O\end{array}$ & $\begin{array}{ll}10 & 14 \\
10 & 16\end{array}$ & $\begin{array}{ll}10 & 25 \\
11 & 00\end{array}$ & $10 \quad 16$ & $2+$ & - & $145_{R}$ & 5 & 1.8 & - & - & - \\
\hline
\end{tabular}

Remarks: $\quad P$ is for the polarimeter at $\lambda=3.2 \mathrm{~cm} ; L R$ is for the large Pulkovo radio telescope; $R$ denotes right-hand and $L$ denotes the left-hand circular polarization of the burst and dominating sunspot group; $O$ denotes optical observations of the flare. The area of the flare is given in millionths of the disk.

1. Most of the bursts were accompanied by solar flares.

2. The bursts are characterized by partial circular polarization, which ranges from 5 to 13 per cent.

3. If there was a dominating active region that determined the sense of polarization of the total solar radio emission, that of the burst corresponded to an extraordinary mode of the dominating magnetic field.

4. The regions were situated in the corona at the height of 0.1 to $0.2 R_{\odot}$ above the photosphere.

5. No fast radial movements of the bursts were observed. At least in the case on 1958 March 3 the velocity measured with the large radio telescope was less than $150 \mathrm{~km} / \mathrm{second}$. 


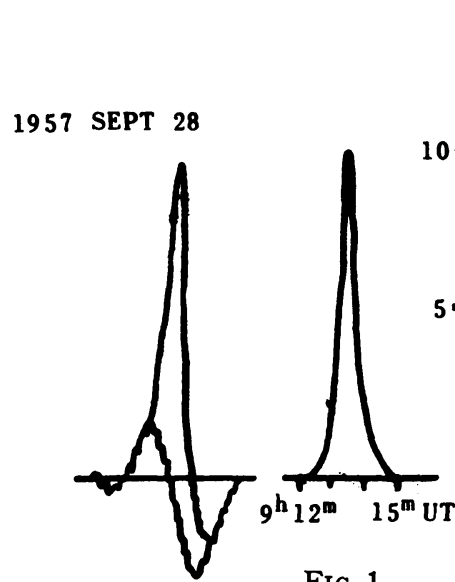

FIG. 1.

$$
\frac{1}{3}
$$

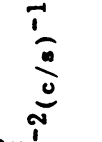

1958 MARCH 21

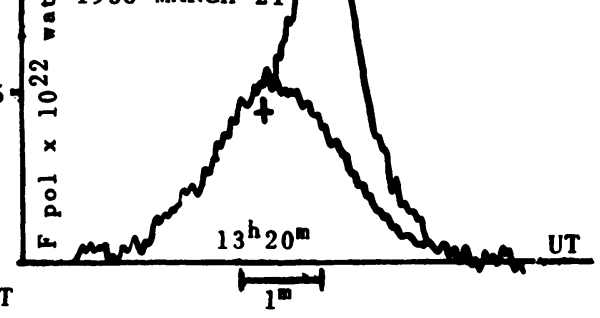

FIG. 2.
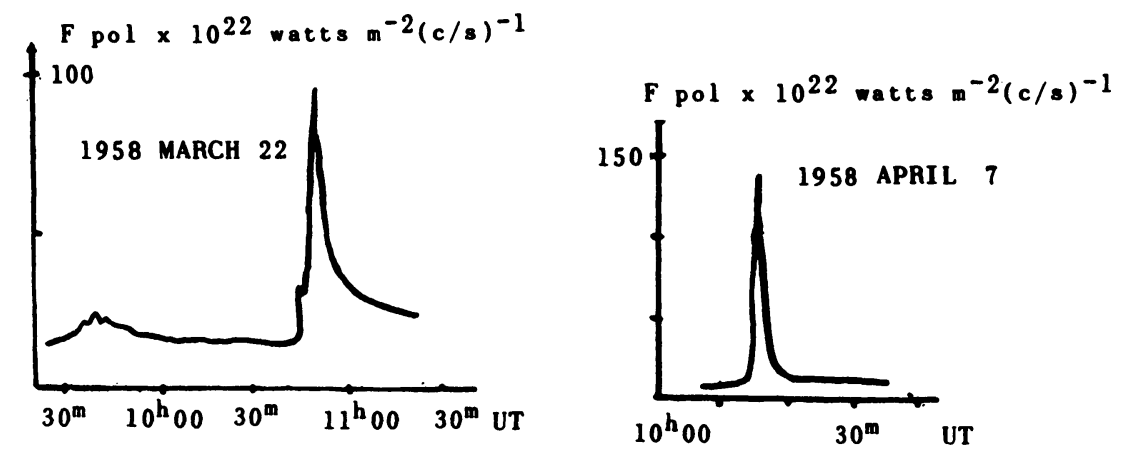

FIG. 3.

Fig. 4.

1957 AUGUST 28

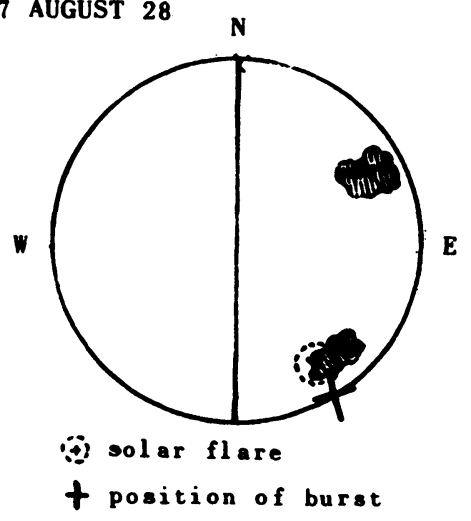

Fig. 5.
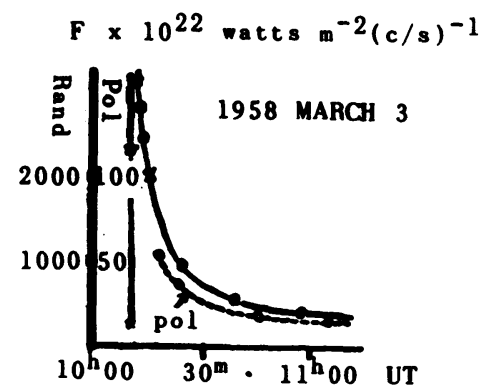

FIG. 6. 
6. The smooth curve with an abrupt growth and an exponential fall is typical. The time constants of these exponents ranged from 0.3 to $15^{\mathrm{m}}$.

7. The area of the burst does not differ significantly from that of the flare.

8. The brightness temperature of $10^{6}$ to $10^{7} \mathrm{~K}$ is usual and it can amount to $3 \times 10^{8}{ }^{\circ} \mathrm{K}$ for some outstanding bursts.

It seems difficult to account for the phenomena observed in terms of plasma oscillations. The plasma frequency for centimeter waves corresponds to an electron density $N_{e}$ about $10^{12}$, which is hardly possible in the observed emission regions. Then the unreal temperature value of around $10^{11}{ }^{\circ} \mathrm{K}$ is necessary to account for the rather large time constant (about $1^{\mathrm{m}}$ ) of plasma-oscillation damping.

If we assume that in some small regions of the corona an abrupt heating takes place which is followed by diffusion of thermal energy, the observed intensity curve would be explained. The quiet appearance of the intensity curve and the sign of polarization (an extraordinary mode) are also in good agreement with the thermal mechanism assumption.

The authors are grateful to Professor S. E. Khaikin for helpful discussion and some valuable suggestions.

\section{REFERENCES}

[1] Kaìdanovskiï, N. L., Korol'kov, D. V., Soboleva, N. S., and Khaïkin, S. E. Solar Data, Moscow, No. 4, 1958.

[2] Transactions of the Fifth Conference on Cosmogonical Questions. Moscow (Acad. Sci. U.S.S.R. Press), 1956, p. 113.

[3] Khaikin, S. E., and Kaidanovskii, N. L. Report on the Plenum of the Radio Astronomy Commission, 1957.

[4] Khaikin, S. E., and Kaidanovskii, N. L. Paper 29.

[5] Kaïdanovskii, N. L., Ikhsanova, V. N., Soboleva, N. S., Timofeeva, G. M., and Gelfreich, G. B. Solar Data, Moscow, No. 3, 1958.

[6] Gelfreich, G. B., Korol'kov, D. V.; and Soboleva, N. S. Report on the Plenum of the Radio Astronomy Commission, 1957.

[7] Kundu, M. R. C.R. 246, 2740, 1958. 